Cuadernos de Filología Clásica. Estudios Latinos

ISSN: 1131-9062

http://dx.doi.org/10.5209/CFCL.62528

\title{
Antenor en Ítaca o la venganza de la razón. Un episodio de la segunda parte de El Antenor (1788) de Pedro Montengón ${ }^{1}$
}

\author{
Josep L. Teodoro Peris ${ }^{2}$
}

Recibido: 23 de julio de 2017 / Aceptado: 22 de julio de 2018

Resumen. El libro II de la segunda parte de El Antenor (1788) de Pedro Montengón reproduce unas circunstancias muy semejantes a las que desarrolla el cuarto libro de la Eneida. Una reina viuda, Penélope, se enamora de un héroe, Antenor, que tiene un destino más alto por cumplir. El tratamiento que el autor da a esta situación difiere sustancialmente del virgiliano, introduciendo elementos propios de la moral estoica, del decoro burgués y de la sensibilidad romántica, en una combinación que denota perfectamente la época de composición de esta interesante novela de trama legendaria y de intenciones filosóficas.

Palabras clave: Ilustración; estoicismo; épica; Eneida; novela; romanticismo.

\section{[en] Antenor in Ithaca or the Revenge of Reason. An episode of Pedro Montengón's El Antenor (1788)}

Abstract. The book II of the second part of Pedro Montengon's El Antenor (1788) describes very similar circumstances to those developed by the fourth book of the Aeneid. A dowager queen, Penelope, falls in love with a hero, Antenor, who has a higher destiny to fulfill. The treatment that the author gives this situation differs substantially from Virgil, introducing elements of Stoic morality, bourgeois decorum and romantic sensibility, perfectly denoting the time of composition of this interesting novel with legendary plot and philosophical intentions.

Key words: Enlightenment; Stoicism; epic poetry; Aeneid; novel; Romanticism.

Cómo citar: Teodoro Peris, J.L, «Antenor en Ítaca o la venganza de la razón. Un episodio de la segunda parte de El Antenor (1788) de Pedro Montengón», Cuad. Filol. Clás. Estud. Lat. 38.2 (2018), 329-344.

El Antenor (1788) de Pedro de Montengón ${ }^{3}$ es una larga narración que cuenta las andanzas de este héroe, hermano de Príamo, desde que parte de Troya la noche de su caída hasta que consigue establecerse finalmente en el territorio de los hénetos para fundar la ciudad que más tarde será Padua. Se trata de una obra que ha sido objeto

$1 \quad$ Este artículo se inscribe en el Proyecto de Investigación FFI2017-83894-P «Diccionario Hispánico de la Tradición Clásica» (2018-2020), dirigido por Francisco García Jurado.

2 Universitat de València, josep.1.teodoro@uv.es. (Id. Orcid 0000-0002-3671-4756).

3 Para un encuadre biográfico de Pedro Montengón, véanse Cerezo Magán (2011) y García Sáez (1974). Excelentes también por su concreción y detalle las notas que presenta Guillermo Carnero en su edición de Montengón (2002, 11-28). 
hasta el momento de pocos estudios ${ }^{4}$, pero interesante hasta el punto de que alguno de sus comentaristas afirma que es uno de los pocos ejemplos en lengua castellana del poema épico en prosa al estilo de Marmontel, Florian y Lantier (Fabbri 1972, 103).

Montengón, por su parte, emplea el término romance para referirse a su obra, distinguiéndola de la novela - es decir, del género en prosa dirigido a la exposición de las experiencias interiores de sus protagonistas y de sus aspiraciones individuales 5 - y aproximándose de este modo a la tradición épica en prosa, cuyas producciones eran conocidas comúnmente como historias, término que nuestro autor también rechaza, para recalcar el carácter mítico y fantástico de su relato (Montengón 1788, III-IV) ${ }^{6}$.

En un esquema de fuerzas que recuerda el de la Eneida de Virgilio, al inicio del relato Antenor se ha granjeado la antipatía del dios Marte y la abierta protección de la diosa Paz por su posición contraria a las hostilidades en la guerra de Troya. ${ }^{7}$ Así, después de una accidentada huida de la Tróade y de un naufragio impulsado por su divino enemigo en las costas del Quersoneso Táurico, donde el protagonista llega a ser rey de los lugareños ${ }^{8}$, nuestro héroe recibe allí un escudo de manos de la Paz en el que están señalados los contornos de la costa que debe encontrar para fundar la ciudad que los dioses le tienen destinada. En búsqueda de alguien que pueda interpretar el mapa cincelado en el escudo, y después de recorrer algunas ciudades de Frigia y Tracia, Antenor dirige su flota a Zacinto, donde espera encontrar información y un piloto experimentado. A nuestro juicio, no es casual la elección de Zacinto; en el momento de redacción de esta obra, la isla era una de las más preciadas posesiones de la Serenísima como baluarte contra el Imperio Otomano.

En la isla jónica reina Plístenes, hijo de Medonte. En la Odisea aparece un heraldo llamado Medonte, que avisa a Penélope de que los pretendientes tienen intención de

$4 \quad$ Entre ellos, cabe destacar los artículos de Román Gutiérrez (1986), V. Cristóbal (1999), Contadini (2013) y la excelente monografía sobre el autor de Blanco Martínez (2001).

5 Álvarez Barrientos $(1991,26)$ expone claramente las diferencias entre historia, novela y romance en la segunda mitad del s. XVIII: "El romance estaba más cerca del mito y de la épica, también de lo poético, mientras que la novela se acercaba a la vida común e intentaba ser artística desde la consideración moral de dicha realidad y su necesidad de explicarla".

6 «La tradición no es siempre verdadera. Las noticias cundidas entre los pueblos sobre su origen, son comúnmente partos de la rusticidad y de la superstición de los tiempos en que fueron concebidas. Todos los pueblos quisieron sacar su origen de las nubes. [...] Tales noticias son mas propias de la epopeya que de la historia [...]. No se deberá estrañar por lo mismo, si á semejanza del que celebró la fundación de Roma, me valgo yo de los mismos adornos épicos para celebrar la fundación de Venecia, pues lo hago en un romance, y no en historia». Para la leyenda de Antenor en su conjunto, $c f$. Braccesi (1984).

7 Como explica Carnero (Montengón 2002, 28-34), los parámetros ideológicos y morales de nuestro autor se muestran con toda claridad en su primera obra poética, las Odas a Filópatro (Ferrara 1778-1779, 3 vols.), en las que expresa sus principios reformistas ligados a la Ilustración moderada. El tema del patriotismo y, especialmente, de la paz, está presente en términos muy semejantes a los que encontramos largamente ponderados en El Antenor: la guerra solo es lícita cuando es defensiva. Montengón sustituye la oposición entre la protectora Venus y su antagonista Juno, que impulsa el drama de Eneas, por la pugna entre Marte, adversario de Antenor, y la Paz, su defensora.

8 Montengón explota en la primera parte de El Antenor el mito de la tradicional nobleza, belicosidad y libertad de los escitas transmitido por las fuentes clásicas, y retomado en el XVII y XVIII por autores como Voltaire en su tragedia Les Scythes de 1767. Con Voltaire nuestro autor comparte una cierta visión negativa de este pueblo en relación a la superioridad de la cultura grecolatina, que no coincide con los representantes de una Ilustración más radical, como Diderot, o de una sensibilidad más cercana al romanticismo, como fueron Rousseau e incluso, desde otro punto de vista, Chateaubriand (David 1938, 1-10). 
asesinar a Telémaco cuando regrese a Ítaca (Hom.Od.4.677) y que es perdonado por Ulises durante la posterior matanza (Hom.Od.22.357)9. También Ovidio (Epist.1.9) nombra un «cruel Medonte» en la carta de Penélope a Ulises, y quizá sea este el origen de la opción de nuestro autor.

Según Montengón, que altera ligeramente la tradición mitológica, Medonte ha sido asesinado por Ulises junto con el resto de los pretendientes de su esposa, y por ello Plístenes recibe gustoso a Antenor, pensando que el troyano albergará contra el héroe griego un resentimiento comparable al que experimenta él mismo. Ambos se juran amistad y alianza, aunque Antenor ignora las intenciones de Plístenes de tomar venganza sobre Ulises, que a la sazón vuelve a reinar en Ítaca ${ }^{10}$.

En Zacinto, mientras Antenor habla con Plístenes en un bosque consagrado a Fauno, aparece un náufrago desnudo que se presenta como Telégono, hijo de Circe y Ulises. Telégono ha abandonado a su madre porque esta le ha dicho que encontraría a su padre en la isla de Ítaca, pero sin comunicarle el nombre de su progenitor.

Inmediatamente, Plístenes concibe un plan para vengarse de Ulises, matando a aquel joven a la vista de su padre. Para llevar adelante su proyecto, que Antenor ignora, solicita que todos se embarquen hacia Ítaca. Antes de llegar a la isla de Ulises, la pequeña escuadra de Antenor y Plístenes intercepta un barco que había partido de Ítaca en dirección a Corcira, y la tripulación de este les informa de que iban al encuentro de las dos naves que traían a Nausícaa, hija de Alcínoo, para contraer en Ítaca matrimonio con Telémaco.

Montengón identifica la isla de los feacios con Corcira (Montengón 1788, II 90), a un par de días de navegación de Ítaca, y hace que este sea uno de los primeros lugares que visite Telémaco en el periplo que emprende para conocer la suerte de su padre. El compromiso de matrimonio entre Nausícaa y Telémaco está recogido ampliamente por los mitógrafos ${ }^{11}$.

Montengón reúne rápidamente a los protagonistas de este pequeño drama: Por un lado, Ulises, que ha culminado su venganza y está poniendo en orden los asuntos de su reino, en medio del resentimiento de las familias de los pretendientes. Junto a él, Penélope y su fiel criada Clímene, que comparte nombre, pero no filiación, con la conocida sirviente de Helena (Hom.Il.3.144). Telémaco está ausente, en Pilos, enviado por su padre para recabar ayuda del anciano Néstor contra la probable venganza de las familias de los pretendientes, y el anciano Laertes está en sus tierras, como había sido su costumbre durante la ausencia de su hijo. Por otro lado, desembarcan en Ítaca Plístenes y su aliado Antenor, que ha conseguido hacerse cargo de la custodia de Nausícaa para ponerla a salvo de la posible venganza del griego. Con ellos llega también a la isla el desgraciado Telégono, ignorante de su linaje y elemento desencadenante de la acción.

9 En todo este fragmento domina la idea de reescribir los comportamientos de los personajes homéricos. Montengón elige, precisamente, a uno de los pretendientes que en la narración homérica no muere a manos de Ulises para convertirlo en víctima desencadenante de la venganza de su hijo Plístenes.

10 Las venganzas de los familiares de los pretendientes asesinados por Ulises fueron tema para algunas tragedias, concretamente una tetralogía de Esquilo, de la que restan algunos fragmentos, que no son lo suficientemente largos para hacerse una idea cabal de su contenido. Cf. Katsouris (1985, 47-60) y Sommerstein (2013, 249-253). Para Montengón (1788, II 84-104), la crueldad innecesaria de Ulises pone en peligro el Estado y lo deshonra ante sus súbditos y ante su familia.

11 Especialmente desde Eustacio de Tesalónica, $c f$. Stallbaum $(1826,117)$. También Telémaco se casa con Nausícaa según Dictis de Creta, 6, 6 . 
El primer acto, muy breve, de este episodio, es el encuentro entre Ulises y su hijo Telégono. Éste último, que agradece la acogida que le ha brindado Plístenes, se ofrece para llevar una embajada a los itacenses: deben entregar a Ulises vivo o muerto, para hacerle pagar por el asesinato de los pretendientes. Es el propio Ulises quien recibe al mensajero, al frente del ejército que ha reunido para repeler el desembarco de los de Zacinto. Telégono desafía a Ulises y en el curso de un breve combate lo atraviesa con su espada. En el momento de su agonía, cuando Ulises, con acento virgiliano, maldice su suerte por no haber muerto gloriosamente ante los muros de Troya en vez de ser abatido por un zacintio desconocido (Montengón 1788, II 96) ${ }^{12}$, Telégono le revela que es hijo de Circe. Ulises, antes de expirar, aún tiene tiempo para informar al desdichado Telégono que ha matado a su padre cumpliendo involuntariamente la venganza de su despechada madre (APOL. epit.7.36-37).

En El Antenor las pasiones siempre son consideradas nocivas; la fogosidad amorosa de Circe, que había mantenido lejos de su hogar a Ulises, es la causa final de la ruina de este. Montengón no sigue la leyenda tradicional sobre estos personajes, y elimina al máximo todas las referencias fantásticas que contenía, pues pasa sobre ella sin mencionar la inmortalidad de la ninfa, de la que habla como de una simple mujer despechada, y explica las transformaciones de los compañeros de Ulises como actos de mera hechicería (Montengón 1788, II 104).

El combate que sigue a la muerte de Ulises simplifica aún más la situación, puesto que Plístenes también cae víctima de las armas itacenses (Montengón 1788, II 98), el ejército de los zacintios vuelve a su isla, y Antenor se encuentra, sin pretenderlo, dueño de la situación.

Empieza así el segundo acto de nuestra pieza, cuando Penélope, sabedora de la muerte de su marido, envía una embajada con regalos al campamento de Antenor, para pedirle la paz. Si prudente es la conducta de la reina viuda, que no desea seguir con las hostilidades, más lo es la respuesta de Antenor, que devuelve los regalos y da toda suerte de seguridades sobre su amistad y buena voluntad, expresando además su deseo de conocer a Penélope y de consolarla por la muerte de Ulises, en la cual él no ha tomado parte alguna. Ante la reina expresa su deseo de romper la cadena de venganzas que la belicosidad de Ulises había desatado, y justifica su presencia en Ítaca para conocer la suerte de su hijo Laódoco, que pudo haber llegado a la isla junto con el resto de cautivos troyanos asignados a Ulises.

Estimulada por las palabras de Antenor, que elogia su fidelidad, Penélope despliega un rencor hacia su esposo muerto que se ajusta mucho más al criterio de la burguesía del último tercio del s. XVIII que a la moral de una princesa aquea.

La muerte de Ulises, a los ojos de su viuda, ha sido mucho más dolorosa porque murió a manos de su hijo ilegítimo, fruto de su relación con Circe. Es posible, añade, que Ulises aún guardase en su pecho amor por aquella hechicera cuando asesinó a los que la pretendían y «que tal vez eran más dignos» (Montengón 1788, II 103). Ulises es un perjuro, un criminal que se ha degradado entregándose a otra mujer, mientras ella se esforzaba en mantener su fidelidad. Su desmedida acción ha desatado una reacción de venganza entre los parientes de los asesinados que pone en peligro la vida de la propia Penélope, la de Telémaco y la estabilidad del reino.

12 «Por qué, antes que á manos de un zacintio, no perecí en Troya vencido por Héctor», que remite a VERG. Aen.1.94-101. 
La reina, además, siente una punzada de culpabilidad ante la muerte de los pretendientes: «Sé lo que me costó mi constante amor en las muertes de Eurimaco, de Polibo, de Pisandro, de Medonte y de Antinoo, muertos barbaramente por él en mi presencia» (Montengón 1788, II 104). De hecho, el resquemor que le deja la traición de Ulises le hace revisar su conducta pasada y, si bien no lamenta explícitamente haber conservado su fidelidad hasta la llegada de Ulises, no piensa continuar con ella una vez muerto; en el coloquio que mantiene acto seguido con su sirvienta Clímene, manifiesta que el único freno que siente actualmente es su hijo Telémaco:

¿Casarme viviendo Telemaco? ¡Ah! Climene, ¿qué proferís? Mi corazon no se rendirá á mi resentimiento. Lo que no me merece el padre infiel, lo debo al amor del hijo inocente. Telemaco pondrá siempre estorvo á la venganza de mi afecto (Montengón 1788, II 106).

La resolución de Penélope de mantener su viudez pierde fuerza después de trabar conocimiento con Antenor, pero es Clímene la que proporciona los argumentos: el honor de las mujeres está sometido «á fatales indicios que exîgen de nosotras mayor recato y constancia». Pero Penélope, ahora que la muerte de su marido la ha liberado de la promesa de fidelidad, debe renunciar a su «ideal obligación» y concederse lo que sus «gracias y hermosuras todavía acreedoras á mas altas pretensiones que la hija de Leda á las de Paris» le permiten conseguir (Montengón 1788, II 106-107).

Así las cosas, ante Penélope se presentan dos problemas: cómo actuar con su hijo Telémaco, y cómo conocer cuál será la decisión de Antenor respecto de Nausícaa, que por derecho de guerra le pertenece. En este último punto, es el propio Antenor el que se encarga de disipar las dudas de la reina, cuando le confirma su intención de casar a Nausícaa con Telémaco, como estaba previsto.

A partir de este momento cobra relevancia el personaje de Clímene, la doncella de Penélope, que adquiere un papel de consejera semejante al de Ana en relación a Dido en el libro cuarto de la Eneida ${ }^{13}$. Clímene desvaloriza a los ojos de Penélope la figura de Ulises, de «animo taimado y artero», el cual, «acostumbrado a la disolución que acompaña á la guerra, pospone todas las demas cosas al ansia de ganarse renombre» (Montengón 1788, II 124). En realidad, a su juicio, el verdadero comportamiento heroico ha sido el de Penélope, que ha conseguido domeñar sus pasiones durante tan largos años; una continuada lucha de su honestidad y constancia que le ha acarreado un sufrimiento «mucho mas heroico que todas sus fieras proezas» (Montengón 1788, II 125).

La heroicidad de Penélope aún es mayor cuando se nos descubre que en su interior, realmente, late un corazón apasionado y de fuertes sentimientos, que oculta bajo una capa de majestuosidad y de contención. Para Montengón no hay virtud en dominar un corazón sin apetitos, apartado del mundo u obligado al aislamiento; la vida retirada o monástica, que nos mantiene lejos de los sentimientos verdaderamente humanos, no tiene nada de virtuoso, puesto que se limita a huir de las pruebas a las que la vida nos somete. Sus héroes están llenos de pasiones, de deseos y de temores, pero logran controlarlos mediante la razón y un sentimiento de humanidad que no es tanto producto de la moral católica — como podríamos esperar de un exjesuita- cuanto

13 Este paralelismo ha sido observado por Cristóbal $(1999,134)$, que señala también otros elementos de intersección entre el hipotexto virgiliano y el producto de la «transgenerización» llevada a cabo por Montengón. 
de un deísmo nada dogmático y siempre dispuesto al compromiso con aquellos que piensan diferentemente.

La moral de los personajes de Montengón no es ecléctica ni depende de las circunstancias. Es una moral práctica basada en la idea estoica de vivir según la naturaleza, es decir, actuar según imponen las circunstancias pero conservando la libertad de acción que solo la razón y el control de las emociones proporcionan. ${ }^{14}$

Con todo, el decoro es un componente importante de la honestidad en la sociedad en la que mueven los personajes de El Antenor, y aunque la viuda Penélope siente que el amor y el respeto que experimentaba por su marido idealizado y ausente ha sufrido un duro golpe cuando ha conocido al verdadero Ulises y ha tenido noticia de su comportamiento, tan alejado de la castidad que ella ha mantenido, le guarda no obstante el luto obligado y contiene los sentimientos que la impulsan hacia el fugitivo troyano.

Siguiendo el modelo virgiliano, después de la recepción de Antenor en palacio se celebra una cena, a la que asisten troyanos, feacios e itacenses. La primera libación corresponde, como es de rigor, a la anfitriona, que pone sus labios sobre la copa de oro y la pasa a Antenor, que la apura «con tanta mayor complacencia, quánto que llevaba impresos los labios, de quien con no menos complacencia se la entregaba» (Montengón 1788, II 119). Al igual que Eneas ante Dido, Antenor relata a Penélope las circunstancias de su viaje, y acaba mostrándole el escudo que la Paz le había entregado en el Quersoneso Táurico. Los acompañantes de Nausícaa — cuyos nombres son, por cierto, de inspiración veneciana, Zenoo, Morosinio, Linoo, Bolduvio y Foscario ${ }^{15}$ - reconocen las costas dibujadas en la prodigiosa defensa y se ofrecen a acompañarlo. La alegría de la concurrencia acaba por hacer olvidar a Penélope su duelo, pero aún más un regalo que le entrega Antenor al final del convite, consistente en un «braserillo de oro de primorosa hechura, y un cofrecillo lleno de preciosos aromas» (Montengón 1788, II 122) que más tarde tendrá un papel preponderante en el desarrollo de esta pieza.

El relato de Antenor impresiona a Penélope, que lo encuentra más creíble «que los Ciclopes, los Lestrigones, los Antifates y los Caribdis de Ulises», siguiendo la línea de racionalismo de la obra.

Montengón conocía bien la obra de Ludovico Antonio Muratori, divulgada y comentada en el círculo de los jesuitas de la provincia de Aragón, y especialmente en la Universidad de Valencia ${ }^{16}$. En su ensayo Della perfetta poesia italiana (1706), Murato-

14 Sobre el estoicismo en Montengón, el primer estudio es de Alarcos Llorach (1940-41, 149-156). Insiste en ello Blanco Martínez (2001, 123-134).

En una reciente edición del Eusebio (1998) de Montengón, Fernando García Lara realiza un excelente estudio sobre el papel del estoicismo en la ideología de nuestro autor, y del conflicto que nace de "la osada pretensión de hacer compatibles la moral natural de la ética clásica con la verdad revelada del catolicismo imperante $(1998,54)$ ". En Eusebio, Montengón trata de soslayar el problema dando al joven educando un ayo cuáquero, pero en El Antenor, situado en la antigüedad clásica, el conflicto con la moral cristiana pasa más desapercibido y la moral estoica de base es mucho más evidente. Véase también Santonja (1989), que incide sobre el mismo tema. Por otro lado, la relación de Montengón con el cuaquerismo, no estudiada en detalle, pero evidente en el comportamiento de Antenor, que se ajusta a los principios de simplicidad, igualitarismo, honestidad y pacifismo tan queridos por esta corriente espiritual, puede llevar a poner de manifiesto la influencia en nuestro autor de Voltaire, máximo difusor en Europa de las virtudes de esta corriente religiosa (Barbar 1963).

15 Es fácil reconocer las familias patricias de los Zeno, Morosini, Lion, Boldù y Foscari. De hecho, Ferigo Morosini era el proveditore (gobernador) veneciano de Zacinto durante la redacción de esta obra (Raines 2003, 2-64), y Francesco Morosini fue uno de los artífices de su conquista. (Luinzi 1858, 240).

16 Para un estado completo de la cuestión, $c f$. Mestre (1968, 403-411) y (1975, III, 173-220). 
ri propone que existen dos potencias del alma relacionadas con la creación: la fantasía y el intelecto. La primera es la facultad imaginativa, que utiliza los sentidos para captar los objetos sensibles y crear nuevas imágenes. La segunda es una facultad racional, que decide si las imágenes creadas por la fantasía son verdaderas o falsas. La relación entre la fantasía y el intelecto es determinante para establecer la belleza en la composición literaria. Una imagen formada solo por la fantasía, sin participación del intelecto, que debe garantizar la presencia de verdad, claridad y orden — principios de la belleza - se acerca más al delirio que a la poesía. Montengón tiene un pobre concepto de los seres creados por la fantasía homérica, que encuentra alejada de lo verosímil para el intelecto. La fuerza del relato, como experimenta Penélope, depende de su verosimilitud, no de la fantasía desplegada en él. La poética de la Odisea goza de poca consideración frente a la racionalidad de las manifestaciones que aparecen en el relato de Antenor. ${ }^{17}$

Durante la cena que la reina ofrece al héroe y en la que se produce el relato de sus aventuras, si bien Penélope no sostiene a Cupido entre sus brazos como hace la sidonia Dido, el amor «se sirve de la compasión y ternura para encender su llama» (Montengón 1788, II 123). En nuestros héroes la pasión no está prohibida, pero no nace de un desorden de los sentimientos, o de una influencia externa, sino de la reflexión y del análisis. Lo que más huella deja en el ánimo de la reina es «la constancia, el amor y la fidelidad» que Antenor había mostrado por su difunta esposa Teana, pero, aunque la reina siente nacer en su corazón un fuerte afecto y atracción hacia nuestro héroe, su viudez es demasiado reciente, y el dolor y la rabia que le han producido la muerte de Ulises demasiado frescos para que decida dar rienda suelta a ese sentimiento, pese a la insistencia de su confidente Clímene.

Como desde la estética de Montengón es poco creíble que sea un dios casamentero el que empuje a Penélope al matrimonio, nuestro autor busca otro mecanismo para impulsar la narración, y lo encuentra en el contenido del cofrecillo que había entregado Antenor a la reina. Cuando Clímene quema unos pocos granos en el brasero que lo acompañaba, sienten que se esparce por sus venas «un sensible alborozo» que «borra del todo á Penélope la memoria de Ulises y su muerte, como si no le hubiese conocido». No es necesario, pues, ningún Cupido, sino más bien una «medicina prodigiosa, que debió encontrar un sabio egipcio, para curar las dolencias del ánimo» (Montengón 1788, II 124). El aparato divino se substituye por la farmacología en el pensamiento contrario a la fábula mitológica de nuestro autor.

El efecto de la droga es limitado, porque no elimina el raciocinio de los que se someten a su influjo. Es la propia Penélope la que ordena a Clímene que cese de quemar los aromas medicinales, puesto que ya ha notado su efecto, y decide que se abstendrá de dar el primer paso — puesto que el decoro se lo prohíbe-, pero no hará nada para impedir que Antenor le proponga matrimonio.

Solo se opone a su determinación el temor de la reacción de Telémaco, pero nuestro autor decide eliminar a este incómodo personaje: Mentor le trae la noticia de la muerte de su hijo a manos de Demódoco, padre de Pisandro, otro de los pretendientes muertos por Ulises. Los desafueros del padre recaen también, pues, sobre el hijo. Es de notar que Montengón, sacando de escena a Telémaco, se opone a la línea abierta por Fenelón en Les aventures de Télémaque (1699), y es más consecuente

Como señala García Lara (Montengón 1998: 32), la Poética (1737) de Luzán también está presente en la elección de los registros temáticos de nuestro autor, que subordina la trama a sus objetivos de restauración moral y de reconstrucción social. 
con la mitología clásica, que en la perdida Telegonía narraba cómo el hijo de Circe y Ulises conducía a Telémaco y a Penélope a la isla de Eea donde se celebraban dobles bodas: de Telémaco con Circe y de Telégono con Penélope (Hyg.fab.127).

Ninguna de estas opciones matrimoniales parece digna a nuestro autor y, así, el incómodo personaje de Telémaco es eliminado antes de aparecer realmente en escena, mientras que, de paso, el autor aprovecha para mostrar las consecuencias que provoca la venganza incontrolada e innecesaria de Ulises en la persona de su inocente hijo. Por fortuna, los prodigiosos aromas que, temiendo lo peor, Clímene se ha apresurado a llevar a la sala, amortiguan el dolor de la madre y del mensajero, que exclama sorprendido al final de su relato: «Esta ha sido la fatal suerte de vuestro hijo Telémaco; y no sé lo que es, que temiendo antes morir de dolor, no puedo ya dolerme de ella después que percibo esta suavísima fragancia» (Montengón 1788, II 128). Por desgracia, las virtudes del braserillo no alcanzan a Laertes, que al recibir la noticia de la muerte de su nieto fuera de palacio, cae fulminado.

Se encuentra así Penélope con el campo expedito: han muerto Laertes, Ulises y Telémaco. Nada se opone a su matrimonio con Antenor, excepto la opinión de los itacenses, que sin duda verían con muy malos ojos que su reina, que había convertido su fidelidad en proverbial, contrajera matrimonio con un extranjero cuando aún están calientes las cenizas de su suegro, marido e hijo.

El contraste que Montengón establece entre su Penélope y la Dido virgiliana es aquí aún más marcado. Ambas son viudas, ambas se encuentran en la necesidad de gobernar un reino, ambas se enamoran de un troyano fugitivo después de haber rechazado otros pretendientes (VERG.Aen.4.34), ambas tienen una persona de confianza que les empuja a contraer matrimonio con su enamorado, atendiendo a sus sentimientos antes que a las convenciones sociales. Pero hasta aquí llega el paralelismo. Para empezar, el carácter de una y otra es muy diferente: el enamoramiento hace perder a Dido el control sobre sus actos; abandona el gobierno de su ciudad y recorre Cartago qualis coniecta cerua sagita (VERG.Aen.4.69) sacrificando en todos los altares, víctima de una pasión que solo hace que aumentar y la lleva a revolcarse, en su soledad, en el lecho que Eneas ha abandonado (Verg.Aen.4.82-83) hasta encontrarse en una situación próxima a la desesperación: ardet amans Dido traxitque per ossa furorem (VERG.Aen.4.101).

Penélope, por su parte, muestra un temperamento mucho más comedido cuando se siente enamorada. Aunque las circunstancias son cada vez más favorables al enlace con Antenor, tiene siempre presente el necesario decoro y el control de sus impulsos.

La segunda entrevista con el troyano, antes de conocer la muerte de Telémaco, es definitiva para aclarar las dudas de Penélope acerca del carácter de este. Antenor, que desea aliviar el dolor de la reina por la muerte de su marido, y que ya ha empezado a concebir esperanzas de ocupar un lugar en su corazón, le pide a esta permiso para traer a palacio a Nausícaa, y hacer que la joven espere allí a su prometido Telémaco.

Penélope recibe con sumo placer esta noticia, que despeja el futuro del reino Antenor no piensa impedir la coronación de Telémaco-y también deja claro que el troyano no desea hacer de la joven su cautiva o su esposa. «Mas para no desmentir su afliccion ni hacer agravio á su luto, recobró inmediatamente la apariencia del dolor» (Montengón, 1788, II 112). A partir de este momento, el dolor y el luto de la reina es más una simulación con fines políticos que una realidad, en contraste con la imprudencia que muestra Dido. 
De hecho, el fingido duelo de Penélope tiene que ver también con el concepto que en la obra se tiene del pueblo, ignorante de sus verdaderas necesidades, infantil y voluble en sus deseos y necesitado de una mano fuerte y paternal que lo guíe. Los itacenses, en lugar de guardar resentimiento a Antenor por haber participado, aunque indirectamente, en la muerte de su rey, aclaman calurosamente el cortejo de feacios y troyanos que acompaña a la princesa Nausícaa a palacio (Montengón 1788, II 116). La pompa del gobierno y la majestad de la presencia real son suficientes para convencer a una masa anónima sin criterio político ni madurez.

También son grandes las diferencias en el momento de consumar el compromiso entre Dido y Eneas por un lado y de Penélope y Antenor por otro. En el primer caso, la escena se desarrolla durante una cacería a la que Dido y Eneas acuden vestidos con sus mejores galas, ella envuelta en una clámide de púrpura y oro; él con una apostura semejante a la de Apolo (Verg.Aen.4.136-150). Cuando la tormenta enviada por Juno les obliga a refugiarse en una cueva y allí consuman su unión, toda la naturaleza participa del connubio, las antorchas nupciales son los rayos de la tempestad, y el himeneo es cantado por las ninfas y el viento entre los árboles. Consecuentemente con el gran aparato que ha acompañado su unión, la reina muestra abiertamente su nueva situación a sus súbditos: neque enim specie famaue mouetur / nec iam furtiuom Dido meditatur amorem: / coniugium uocat, hoc praetexit nomine culpam (VERG.Aen.4. 170-172). Tampoco Eneas se muestra más cauto, y ambos, regnorum immemores turpique cupidine captos (VERG.Aen.4.194), pasean su amor por toda la ciudad.

Penélope y Antenor están bien lejos de secundar esta turpis cupido de Dido y Eneas. Su relación se mantiene continuamente a cubierto dentro de los muros de palacio. Como corresponde al decoro, es Antenor el primero en declarar sus intenciones, y lo hace muy formalmente - sin dejar de lado una punta de ironía que planea sobre toda la obra, pues dice que se considera más afortunado que los anteriores pretendientes de Penélope, porque no debe temer la venganza de Ulises-. La reina acepta «alborozada» su requerimiento, pero apunta que debe «atender al decoro de mi estado y á todas mis circunstancias, las quales deben poner la dilacion conveniente á vuestros deseos y mios, á fin de que sea mas cumplida la dicha que de momento $\tan$ feliz nos prometemos».

Antenor la secunda con estas palabras:

Reina, el decoro de vuestro estado lo puede conservar para con el pueblo el secreto de la execucion de nuestros deseos. Un mismo palacio nos hospeda : en él nos puede coronar el himeneo, admitiendo solo por testigo al sacerdote que debe entender en la ceremonia : el pueblo lo sabrá quando convenga (Montengón 1788, II 131).

Penélope muestra de puertas adentro un «apasionado afecto», pero exteriormente no descuida el duelo de su viudez y de la muerte de Telémaco. Cierto es que «la poderosa virtud de los perfumes» (Montengón 1788, II 132) tiene un importante papel en toda esta pieza, e impulsa irresistiblemente hacia la felicidad a aquellos que se someten a sus influjos, pero no hasta el punto de hacerles perder la prudencia que, junto con el disimulo, es la principal arma del gobernante..$^{18}$

18 Sin entrar en un estudio sobre el tratamiento de la llamada "razón de Estado" en El Antenor, nos limitamos a apuntar la evidente conexión ideológica con la literatura política española del s. XVII. Cf. Krabbenhoft (2001) y Badillo-Pastor (2013). 
La felicidad, en todo caso, es un tema muy presente en la mentalidad de nuestro autor, pero no entra en contradicción con la idea de la virtud que nos expone. De hecho, a lo largo del s. XVII se elabora un sólido compromiso filosófico entre las pulsiones de la naturaleza y las exigencias de la rectitud moral de matriz cristiana, que tiende a establecer «une alliance du plaisir et de la raison contre la passion» (Mauzi 1979, 639). Esta conciliación que presenta Montengón entre la naturaleza - que tiende al placer_- y la razón — que es la principal facultad del orden y del decoro-, evoluciona durante el s. XVIII hasta decantarse decididamente por una felicidad que no es solo la conciliación entre el placer y la inteligencia, sino algo más complejo. La inteligencia necesita el impulso de la exaltación para acceder a los secretos del sentimiento e incluso de la metafísica, rehabilitando la pasión como una fuerza poderosa y benéfica de la naturaleza humana.

Este paso, fundamental para entender el concepto de felicidad que aparece en la Declaración de Independencia de los Estados Unidos de América o en el artículo $1^{\circ}$ del Acta Constitucional francesa de $1793^{19}$, es doblemente revolucionario. En primer lugar, porque establece la felicidad individual como derecho personal por el que cabe luchar, desplazando así al concepto antiguo de felicitas, que era más bien un estado de «buena fortuna», independiente de las acciones humanas, y ligado al azar o a la voluntad divina, e invadiendo campos de la beatitudo cristiana y estoica. En segundo lugar, porque para garantizar el acceso a la felicidad se legitima el derecho del pueblo a formar gobiernos y a derrocarlos, si estos atentan contra este principio. ${ }^{20}$

El Antenor recoge en parte esta nueva visión de la felicidad como producto del esfuerzo personal, y consigue un compromiso entre una visión cercana al estoicismo, que hace de la posesión de la virtud causa suficiente de la felicidad, con el principio romántico de la felicidad entendida como la efectiva consecución de los apetitos del ánimo, pero no llega a dar el paso de rehabilitar la pasión a costa del decoro. En este sentido, como en otros muchos de sus posicionamientos ideológicos, se mantiene en unas premisas morales muy moderadas dentro del panorama ilustrado.

En el caso de Penélope, es evidente que la búsqueda de la felicidad se centra en compensar sus años de soledad con un rápido matrimonio con Antenor. Lo cierto es que ese comportamiento contrasta con la constancia y la fortaleza estoicas que había mostrado Penélope durante todo el periodo de ausencia de su marido. Es quizá por eso que Montengón recurre al expediente de alterar el juicio de Penélope mediante los prodigiosos aromas egipcios. No es fácil introducir un elemento romántico en un severo contexto de virtud y de constancia como el que caracterizaba a la reina Penélope, pero el cambio de época y los nuevos valores de la burguesía ilustrada encuentran su lugar en la obra de Montengón, aunque sea gracias al expediente de someter a los protagonistas a la influencia de substancias psicotrópicas.

La droga, con todo, actúa sobre la tristeza y el dolor, no sobre la sensatez, y permite a la reina alcanzar la felicidad sin perder de vista su prestigio y su dignidad,

19 En la Declaración de Independencia de los Estados Unidos se lee: «Sostenemos como evidentes estas verdades: que todos los hombres son creados iguales; que son dotados por su Creador de ciertos derechos inalienables; que entre éstos están la vida, la libertad y la búsqueda de la felicidad”. Encontramos el mismo principio en el art. $1^{\circ}$ del Acta Constitucional Francesa de 1793: "El fin de la sociedad es la felicidad común».

20 McMahon (2005, 12-13) señala el nuevo dinamismo que el concepto toma entre los ilustrados, alejándose de la beatitudo estoica, interior e independiente del entorno, y tornándose un concepto más dinámico y relacionado con las circunstancias que rodean a la persona, lo que tiene como natural respuesta la voluntad de modificar las condiciones externas para garantizar el «derecho» a disfrutar de esa felicidad. 
como sucede a Dido. Para Montengón, el amor es una pasión serena y benéfica, lejos del trastorno rayano en la locura que Virgilio atribuye a este sentimiento ${ }^{21}$.

La conclusión de la pieza, siguiendo el modelo virgiliano una vez más, inicia cuando Antenor recibe, mientras estaba sacrificando ante el sepulcro de Laertes, la visita de la Paz, que le recuerda su destino:

¿Dexaste, por ventura, Antenor, el reyno y trono del Chersoneso para venir á encerrarte con Penélope en estos escollos de Itaca?

Aunque la escena parafrasea la aparición de Mercurio ante Eneas (Verg. Aen.4.265-278), el tono y el contenido presentan ciertas diferencias, producto de la reinterpretación que Montengón hace de la figura del héroe virgiliano. De hecho, gran parte de El Antenor se transforma en una revisión de la Eneida: Antenor y Eneas parten juntos desde Antandros, se separan en Tracia, donde han contemplado juntos el prodigio de Polidoro (Verg.Aen.3.45), dispuestos a cumplir el destino que les han anunciado los dioses. Viven ambos una historia de amor con muchos puntos de contacto, pero también con diferencias significativas: Virgilio pone en boca de Mercurio palabras que echan en cara a Eneas su sumisión a una mujer:

\section{[...] Tu nunc Karthaginis}

altae fundamenta locas pulchramque uxorius urbem

extruis, heu regni rerumque oblite tuarum (VERG.Aen.4.265-268)?

El adjetivo uxorius solo puede ser entendido como "propiedad de la esposa»y, en el contexto, un hombre sin voluntad propia. Este matiz no aparece en las palabras que la Paz dirige a Antenor. Encerrarse en unos escollos con Penélope no parece someterse a la voluntad de esta, sino olvidar lo que le reserva el destino:

De ti quieren los dioses ver echado el cimiento sobre el mar á otra ciudad, que escogeré yo en la tierra por mi principal asiento; de cuyo pueblo y señorio republicano recibiré el mas puro culto: y yo haré que su duración sea igual á su felicidad y á la de sus fieles habitadores (Montengón 1788, II 134).22

Aquí es donde las diferencias entre el destino de Eneas y el de Antenor son más marcadas. Cuando Júpiter se percata de la inacción de Eneas, se lamenta así ante Mercurio:

$21 \quad$ La responsabilidad de Penélope como reina confiere a su modo de actuar características ligeramente diferentes a las otras heroínas montengonianas, como es la permanente conciencia de la razón de Estado. Cf. Insúa Cereceda (2006).

22 En el año de publicación de El Antenor, sin embargo, el mito de Venecia como república perfecta distaba mucho de gozar de buena salud. Montesquieu, durante su grand tour de juventud quedó impresionado del espíritu de corrupción que reinaba en las ancestrales instituciones de la Serenísima (Manuel 1984, 225-228). El punto de vista acrítico de Montengón hacia la constitución esta república se puede deber al hecho de que nuestro autor se estableció en Venecia cuando contrajo matrimonio con Teresa Gayeta en 1788, el mismo año de la publicación de El Antenor. No obstante, la traducción italiana de la obra realizada en 1790 por su hermano, José Montengón, que era secretario en Venecia del conde Alessandro Pepoli, fue decomisada por la Inquisición veneciana (Blanco Martínez 2001, 52-53). 
non illum nobis genetrix pulcherrima talem promissit Graiumque ideo bis uindicat armis; sed fore qui grauidam imperiis belloque frementem Italiam regneret, genus alto a sanguine Teucri proderet ac totum sub leges mitteret orbem (VERG.Aen.4.227-231).

Eneas es un héroe destinado a la lucha. Italia, preñada de imperios, hierve de guerras, y los descendientes del troyano someterán todo el mundo a sus leyes. Antenor, sin embargo, más que una tierra prometida, hallará una ciudad sobre el mar, que no tendrá caudillos militares, sino que gozará de un gobierno republicano, y que será, mientras dure, la patria de la felicidad.

A los muy difundidos comentarios que describen a Venecia como la patria de la libertad y de la justicia ${ }^{23}$, y que elogian la constitución de su república aristocrática como el mejor medio de conseguir el equilibrio entre el principio democrático y la autoridad monárquica, en línea con el comentario ciceroniano sobre la constitución de la República Romana, Montengón les añade una preocupación propia de su época, la consecución de la felicidad.

Pero, de hecho, la Serenísima no era ya un estado modelo en vísperas de la Revolución Francesa, porque su sistema político no encajaba los ideales de igualdad política de la Ilustración, y no tenía la suficiente vitalidad para adaptarse al cambio de los tiempos. Su propio prestigio, la fuerza de una propaganda secular, y, sobre todo, el absoluto control que ejercía la aristocracia sobre los mecanismos de gobierno impedían el necesario aggiornamento de sus instituciones.

Es muy probable que Montengón fuera consciente de esto, puesto que era un hombre atento a los cambios sociales, y en el propio El Antenor describe una ciudad utópica, Elime ${ }^{24}$, con características dignas de más profundo análisis que no tienen cabida en este artículo. En la obra que nos ocupa, sin embargo, no parece querer entrar más allá del elogio a la ciudad que le había acogido, sin poner en cuestión su modo de gobierno.

En principio, la aparición de la Paz tiene el mismo efecto sobre Antenor que la teofanía de Mercurio sobre Eneas. Su primera idea es salir rápidamente de İtaca, pero también aquí aparece una importante diferencia de carácter entre nuestros dos héroes. Herido vivamente del reproche de la diosa, el troyano quisiera partir al instante y alejarse de Ítaca.

¿Pero cómo podía desamparar á su amada Penelope? ¿Y cómo se había de explicar con ella sobre su partida repentina? Resolverla y executarla sin prevenirla antes, pareciale una acción indigna de su corazón magnánimo y generoso (Montengón 1788, II 134).

Al contrario que Eneas, que tiene a su flota anclada y ociosa en el puerto, Antenor ha utilizado sus barcos para buscar a su hijo Laódoco por el litoral del Peloponeso y para pedir amistad a Néstor de Pilos y a Protoo de Beocia, en previsión de una larga

23 Los testimonios alabando la peculiar estructura política de Venecia son numerosos y constantes hasta la desaparición de la Serenísima y aún más allá (Casini 2002, 15-36).

24 Fabbri $(1984,54)$ habla de microutopías para referirse a estos relatos enmarcados en algunas obras de nuestro autor. Un análisis del episodio de Elime en Contadini (2013). 
estancia en Ítaca. Imposibilitado, pues, para cumplir inmediatamente las órdenes de la diosa, dispone de tiempo para pensar de qué manera comunicar sus intenciones a Penélope. De todos modos, su intento está a punto de no tener buen final, porque la reina, pese a la prudencia de nuestro héroe, no está dispuesta a atender a razones y le interrumpe muy alterada:

¿Qué? ¿Pretendeis partir y desampararme tan indignamente despues que me hicisteis consentir en un secreto himeneo, y despues que me dí yo misma, mi trono y mi reyno?

Pero Penélope, pese a que se siente herida en lo más hondo, deja una puerta abierta a la negociación, pues parece dispuesta a acompañarle desde un primer momento:

¿Temeis que llegue el tiempo en que yo pueda acompañaros y seguir sin nota, á lo menos de mi decoro, á un ingrato que me robó la fama, el corazon y el reyno?

$\mathrm{Y}$ este es precisamente el plan de Antenor, que no había tenido tiempo de explicarse convenientemente:

Solo la insinuacion de mi partida no merece la nota de ingratitud tan fea, quando unicamente os la propongo para concertarla con vos misma, y para executarla con vuestro conocimiento. ¿Partir y desampararos en Itaca, huyendo de ella como un ladron de vuestra fama y decoro con el pretexto de obedecer a los dioses? No, Penelope, los dioses que me ordenan la partida no querrán ciertamente que la execute como pirata, sino como conviene y corresponde al hijo de Laomedonte y á un marido de Penelope (Montengón 1788, II 137).

Montengón reescribe la separación de Eneas de Dido con una severa crítica al modo de proceder del héroe. Es una constante en Montengón rechazar como supersticiosos los preceptos de los dioses que no se ajustan a la razón. Una orden de los dioses nunca puede justificar, por tanto, un comportamiento cobarde o indigno como tuvo Eneas con Dido.

Penélope, por su parte, no tiene las responsabilidades de la reina de Cartago, ni su pueblo se configura como el futuro gran enemigo de los antenóridas. Su posición es mucho más cómoda, y no le resulta complicado mostrar una actitud favorable a la voluntad del troyano.

Cuando Antenor le propone abandonar Ítaca con él y dejar el gobierno de la isla en manos de Telégono y Nausícaa — que lo debe tomar por esposo-, la reina acepta sin ninguna oposición los planes de Antenor y deciden embarcar juntos. Aunque todavía queda alguna complicación que resolver, en lo sustancial este es el final del paso del troyano por Ítaca.

A nuestro juicio, resulta evidente el propósito del autor de corregir algunos aspectos del libro cuarto de la Eneida en este episodio de Antenor y Penélope incluido en la segunda parte de El Antenor. Lo sugestivo del intento es la novedad del procedimiento: la crítica a la estética homérica y —en menor medida - virgiliana, se había difundido en los ambientes del clasicismo francés, pero atendía sobre todo a cuestiones de gusto y de bienséance que chocaban con los estrechos criterios del academicismo. En Montengón encontramos una revisión más profunda, que atañe a los impulsos íntimos de los personajes y a su propia constitución moral. 
Antenor es un personaje de gran integridad ética, movido continuamente por impulsos humanitarios. En él la razón siempre gana a emoción, las grandes desgracias que padece no lo llevan a la desesperación, e interactúa con el resto de los personajes de manera didáctica. La influencia del Télémaque de Fénelon no es profunda; la intención de mejorar el comportamiento de los héroes virgilianos es más evidente. $E l$ Antenor no es una novela de aprendizaje, como El Eusebio, sino una novela de tesis; su protagonista no evoluciona como consecuencia de sus vivencias, sino que actúa en ellas con una profunda convicción - la necesidad de la paz y del diálogo para establecer las relaciones humanas - que son producto de sus experiencias durante la guerra de Troya.

La ciudad que espera fundar el héroe debe ser el asiento de la Paz, una república duradera y estable, en contraposición a la Italia que clama por la guerra que nos presenta Virgilio. Montengón reutiliza el mito de Venecia para proponer un nuevo modelo de conquista y de civilización. La Eneida es una epopeya fundacional, el objetivo de su héroe es dar paso a una estirpe que dominará el mundo. Antenor no tiene ese cometido, sino demostrar cómo es posible establecer una relación basada en el diálogo y en la mutua confianza incluso entre pueblos que han sido recientemente enemigos.

En cuanto al tratamiento del amor, que se desarrolla en este episodio, observamos que Montengón no desprecia las pasiones humanas, al contrario, las considera la fuente de la felicidad, pero siempre que se hallen sometidas a la razón y al decoro.

Sin la aceptación social no es imaginable la tranquilidad de ánimo. Es lícito esconder los sentimientos hasta que se han conseguido las circunstancias externas adecuadas para ostentarlos, y para ello es necesario el raciocinio y la inteligencia. La pasión desordenada, como la de Dido, es fuente de desgracias. La frialdad de una Penélope desengañada por la traición de Ulises tampoco constituye un estado de ánimo adecuado, y falto de tiempo para lograr un restablecimiento moral de la protagonista por medio del diálogo y la reflexión, que son las armas con las que cuenta el autor en toda su obra, en este caso recurre al efecto prodigioso de unas raras esencias.

Antenor, ante el amor, es más frío que Penélope, pero no menos decidido. Ante todo, es claro en sus deseos, en contraste con la cobardía e indecisión de Eneas. Los dioses pueden influir en nuestra voluntad, pero no hasta el punto de que olvidemos que, dentro del plan que nos reserva el destino, hay un espacio para luchar por la felicidad individual sin abandonar el ideal colectivo o el caudillaje de una empresa formidable.

Pese a la insistencia en la preeminencia de la razón, la felicidad del héroe montengoniano no se acerca a la insensibilidad estoica, desde el momento en que las pasiones no solo no están prohibidas, sino que sirven de acicate para ser feliz. Las pasiones deben ser moduladas por medio de la razón, del sentido común y de la bondad de corazón. La imperturbabilidad del sabio tiene como límite la necesaria simpatía hacia el prójimo.

Hay en la obra de Montengón un humanismo profundo y cosmopolita que representa los más bellos principios de la Ilustración. El principio de voluntad individual, de destino personal y de derecho a la felicidad que se inicia con la novela preciosista francesa y que veremos desarrollarse plenamente durante el romanticismo, está presente en El Antenor. Hay en él un interesante equilibrio entre la austera moral del deber que alimentaba a los héroes virgilianos y la nueva sensibilidad que enfoca la épica desde la peripecia personal. Es, sin duda, un excelente 
ejemplo de una obra entre dos épocas, que merece mayor atención de la que ha recibido hasta este momento.

\section{Bibliografía}

Alarcos Llorach, E. (1940-41) «El senequismo en Montengón», Castilla I, 149-156, reproducido en Alarcos (1976), Ensayos y estudios literarios, Madrid, Júcar, 23-36.

Badillo O’Farrell, Pablo - Pastor Pérez, Miguel (eds.) (2013), Tácito y tacitismo en España, Barcelona, Anthropos editorial.

Barbar, W. H. (1963) «Voltaire and Quakerism: Enlightenment and the inner Light», Studies on Voltaire and the Eighteenth Century, Theodore Besterman (ed.), Oxford, Voltaire Fundation, vol. 24.

Bernabé, A., ed (1979), Fragmentos de épica griega arcaica. Gredos, Madrid.

Blanco Martínez, Rogelio (2001), Pedro Montengón y Paret (1745-1824). Un ilustrado entre la utopía y la realidad. Valencia, Colección Letras Humanas, Universidad Politécnica de Valencia.

Braccesi, Lorenzo (1984), La leggenda di Antenore. Da Troia a Padova, Padua, Signum.

Casini, Matteo (2002), «Fra città-stato e Stato regionale: riflessioni politiche sulla Repubblica di Venezia in età moderna», Studi Veneziani, XLIV.

Cerezo Magán, Manuel (2011), «Pedro Montengón, jesuita y literato alicantino del s. XVIII; su impronta clásica», Nova Tellus, 29, 1, pp. 175-225.

Cristóbal, Vicente (1999) «El Antenor de Pedro Montengón, una novela virgiliana», Actes del XIII Simposi de la Secció Catalana de la SEEC, Tortosa, pp. 133-136.

Contadini, Luigi (2013), «Estado y utopía en El Antenor de Pedro Montengón», Hacia 1812 desde el siglo ilustrado: Actas del V Congreso Internacional de la Sociedad Española de Estudios del Siglo XVIII, pp. 645-656.

David, Jean (1938) «Les Scythes et les Tartares dans Voltaire et quelques-uns de ses contemporains», Modern Language Notes, Vol. 53, n 1, 1-10.

Fabbri, Maurizio (1972) Un aspetto dell'Illuminismo spagnolo: L'opera litteraria di Pedro Montengón, Pisa, Editrice Libreria Goliardica.

- (1984), Vagabondi, visionari ed eroi, Abano Terme, Piovan Editore.

García Sáez, Santiago (1974), Montengón, un prerromántico de la Ilustración, Alicante, Publicaciones de la Caja Provincial de Ahorros de Alicante.

Insúa Cereceda, Mariela (2006), «La mujer modélica en la novela española: Pedro Montengón», Revista chilena de literatura, nº 69, pp. 113-126.

Krabbenhoft, Kenneth (2001), Neoestoicismo y género popular, Salamanca, Ediciones Universidad de Salamanca.

Katsouris, A. G. (1985), «Aeschylus» Odyssean Tetralogy», Dioniso 53.

Luinzi, Ermanno (1858), Della condizione politica delle isole Jonie sotto il dominio Veneto preceduta da un compendio della storia delle isole stesse dalla divisione dell'Impero Bizantino, Venezia.

Manuel, Frank (1974), El pensamiento utópico en el mundo occidental II. El auge de la utopía: La utopía cristiana (siglos XVII-XIX), Madrid, Taurus.

Mauzi, Robert (1979 [1960]) L'Idée du bonheur dans la littérature et la pensée françaises au xviiie siècle, Slatkine.

McMahon, Darrin (2005), Una historia de la felicidad, Taurus. 
Mestre, Antonio (1968), Ilustración y reforma en la Iglesia. Pensamiento político-religioso de D. Gregorio Mayans i Siscar, Valencia.

Mestre, Antonio (1975 [1972]) «Muratori y la cultura española», La fortuna de Muratori, Atti del Convegno Internazionale di Studi Muratoriani, Florencia, [Módena].

Montengón, Pedro (2002), El Rodrigo, Guillermo Carnero ed., Cátedra.

- (1998) Eusebio, Fernando García Lara, ed., Cátedra.

- (1778-1779) Odas a Filópatro, Ferrara, 3 vols.

Raines, Dorit (2003), «Cooptazione, aggregazione e presenza al Maggior Consiglio: le casate del patriziato veneziano, 1297-1797», Storia di Venezia - Rivista, I, 2-64.

Román Gutiérrez, Isabel (1986), «Un capítulo de historia de la novela española en el s. XVIII: La novela ilustrada de Pedro Montengón», Philologia Hispalense, fascículo, I. Vol. IV, Sevilla.

Santonja, Pedro (1989) "La presència de la naturalesa i la influència de la doctrina estoica en l'Eusebio de Pedro Montengón”, Afers: fulls de recerca i pensament, Vol. 4, N. 8, 19881989, págs. 441-465.

Stallbaum, Gottfried, ed. (1826), Eustathii archiepiscopi Thessalonicensis Commentarii ad Homeri Odysseam, Tom. II, Lipsiae, 117. < https://archive.org/details/commentariiadhom02eust> [20/07/2017].

Sommerstein, Alan (2013), Aeschylean Tragedy, A\&C Black, 249-253. 